\title{
Thermal oxidation process improved corrosion in cobalt chromium molybdenum alloys
}

\author{
H. Mas Ayu ${ }^{1, *}$, R. Daud ${ }^{1}$, A. Shah ${ }^{2}$, M. Y. Mohd Faiz ${ }^{3}$, H. M. Hazwan ${ }^{4}$, M. S. Salwani ${ }^{1}$, S. H. Tomadi ${ }^{1}$, M. S. Reza ${ }^{1}$ \\ ${ }^{1}$ Faculty of Mechanical Engineering, Universiti Malaysia Pahang, Pahang, Malaysia \\ 2Universiti Pendidikan Sultan Idris, Perak, Malaysia \\ ${ }^{3}$ Kulliyyah of Dentistry, International Islamic University Malaysia, Kuantan, Malaysia \\ ${ }^{4}$ Faculty of Mechanical Engineering, Universiti Teknologi Malaysia, Johor Bahru, Malaysia
}

\section{A R T I C L E I N F O}

\section{Article history:}

Received 2 February 2017

Received in revised form

29 July 2017

Accepted 29 July 2017

\section{Keywords:}

Co-Cr-Mo alloy

Thermal oxidation

Corrosion

Oxide interlayer

Surface modification

\begin{abstract}
A B S T R A C T
The corrosion phenomena are always give bad impact to any metal products including human implants. This is due to the corrosion impacts are harmful for hard tissues and soft tissues. There are many methods to prevent the process of corrosion on implant materials such as coating with bioceramic materials and modify the implant surface with surface modification techniques. However, until now there is still no gold standard to overcome this problem and it is remain in researching process. Thus, the aim of this research is to investigate the potential and economical surface modification method to reduce the corrosion effects on Cobalt-Chromium-Molybdenum (Co-Cr-Mo) based alloy when insert in human body. The thermal oxidation process was selected to treat Co-Cr-Mo surface substrate. Firstly, Co-Cr-Mo alloy was heated in muffle furnace at constant temperature of $850^{\circ} \mathrm{C}$ with different duration of heating such as 3 hours and 6 hours in order to analyze the formation of oxide layer. The corrosion behaviours of untreated sample and oxidized sample were investigated utilizing potentiodynamic polarization tests in simulated body fluids (SBF). The Vickers hardness after corrosion testing was measured in order to evaluate the effect of thermal oxidation in reducing corrosion rate. Based on the results obtained it is clearly showed that substrates undergone thermal oxidation with 6 hours duration time performed better than 3 hours duration, with the hardness value $832.2 \mathrm{HV}$ vs. $588 \mathrm{HV}$ respectively. Dense oxide layer and uniform thickness formed on the oxidized substrates able to help in reducing the corrosion effects on Co-Cr-Mo alloy without degraded its excellent mechanical properties. The microstructures of oxidized substrates before and after corrosion test were also analyzed using FESEM images for better observations. It was determined that corrosion resistance of Co-Cr-Mo substrate can be increased with oxide layer formed on the alloys using thermal oxidation process.
\end{abstract}

(C) 2017 The Authors. Published by IASE. This is an open access article under the CC BY-NC-ND license (http://creativecommons.org/licenses/by-nc-nd/4.0/).

\section{Introduction}

Nowadays, the uses of metallic biomaterials have widespread in replacing the damaged hard tissues of the human body due to their excellent mechanical properties such as high corrosion resistance, wear resistance, fatigue strengths and toughness (Mass Ayu, 2015; Afolaranmi et al., 2011; Bikramjit and Mitjan, 2011; Tsaousi et al., 2010). The implants either are used for arthritis treatment or

\footnotetext{
* Corresponding Author.

Email Address: masszee@ump.edu.my (H. Mas Ayu) https://doi.org/10.21833/ijaas.2017.09.020

2313-626X/C 2017 The Authors. Published by IASE.

This is an open access article under the CC BY-NC-ND license

(http://creativecommons.org/licenses/by-nc-nd/4.0/)
}

broken bones treatment due to traumatic accidents. The treatments which involve with inserting material in human body really demand the effectiveness of human implant in term of chemical, physical and biological properties (Mohd Faiz et al., 2014).

In making the human implant which normally used biomaterials such as Titanium, Cobalt based alloy and stainless steel the knowledge of material science which merged the engineering and medical field study are really important (Shirdar et al., 2016; Mas Ayu, 2015). There is a discovery of large possibilities in choosing materials for biomaterial applications. Precious metal which develops the beneficial mechanical properties will probably be taking into consideration and be the first option to 
be utilized into a biomedical product. Geetha et al. (2010) also reported that mechanical properties of the metal and alloys are generally highly counted on their microstructure properties (Mohd Faiz et al., 2014; Geetha et al., 2010).

Another major aspect need to be considered is biological response after implantation. The good mechanical properties of implants are also related to the contact of the implant and human hard tissues. Even though, basic requirement of an implant material is to have good hardness, excellent corrosion and erosion resistance with good wear resistance, interaction between the tissues-implant interfaces is also play an important role (Mas Ayu et al., 2017; Giacchi et al., 2011; Geetha et al., 2010; Guocheng and Hala, 2010; Paital and Dahotre, 2009). Hence, surface modification of biomaterial implants is always aimed at modifying the material while still maintaining the bulk mechanical properties of the implant.

Cobalt-Chromium-Molybdenum (Co-Cr-Mo) alloys are one of the most commonly used for biomedical applications. The main element in this alloy is cobalt ( $\sim$ wt.60\%), chromium $(\sim$ wt.30\%) and molybdenum ( $\sim$ wt. $8 \%$ ). The presence of small amounts of element such as molybdenum is to give a very good high temperature properties while, addition of chromium can helps in improving the corrosion resistance (Shirdar et al., 2016; Paital and Dahotre, 2009).

Regardless of excellent mechanical properties, when Co-Cr-Mo alloy is used as implant inside the human body this materials are still prone towards aqueous corrosion due to the harsh aqueous environment that containing various anions $\left(\mathrm{Cl}^{-}\right.$, $\left.\mathrm{HCO}_{3}{ }^{-}, \mathrm{HPO}_{4}{ }^{2-}\right)$, cations $\left(\mathrm{Na}^{+}, \mathrm{K}+, \mathrm{Ca}^{2+}, \mathrm{Mg}^{2+}\right)$, organics substances and dissolved oxygen (Paital and Dahotre, 2009). Although there are extensively studies in surface modification technique such as plasma spray, electrodeposition, sol-gel coatings and laser deposition but recently, attempts are focusing more on method that is more economical, environmental friendly and simple to be applied (Asri et al., 2016). Thus, the aim of this study is to investigate the potential and yet cheaper with simple method of surface modification to reduce the corrosion rate in Cobalt-Chromium-Molybdenum (Co-Cr-Mo) based alloy. Therefore, thermal oxidation is choose as surface modification method to alter CoCr-Mo alloy surface because of its require less expensive equipment and not need high skills person to operate this process. This results is not only able to maintain its mechanical properties but also improved in corrosion resistance by pertaining finer grain size.

\section{Materials and methods}

\subsection{Substrate preparation}

Cobalt-Chromium-Molybdenum alloy (Co-Cr-Mo) bar was cut using a precision cutter (Buehler, Isomet 4000 ) into disc size of $14 \mathrm{~mm}$ diameter and $2 \mathrm{~mm}$.
All samples were ground using Struers Grinding and Polishing machine (Tegramin-25) to obtain similar surface roughness. Small variation in surface roughness between samples will not significantly influence the adhesion strength of the oxide layer formed after thermal oxidation process. They were wet ground using \#180, \#200, \#400 and \#600 grit $\mathrm{SiC}$ paper. After grinding process, the surface roughness of all substrate was measured using Mitutoyo SJ-301 surface profilometer. The average roughness of ground samples was $0.1 \pm 0.02 \mu \mathrm{m}$. Ground samples were left to dry for overnight in the oven at $50 \circ \mathrm{C}$ before they were taken for next process.

\subsection{Thermal oxidation process}

All samples were placed on the crucible holder and then heated at constant temperature of $850^{\circ} \mathrm{C}$ for 3 hours and 6 hours duration in a muffle furnace. After thermal oxidation process, the samples were left inside the furnace to cool. The thermal oxidation was done in an atmospheric condition at specific temperature in order to obtain finer grain size and higher hardness as mentioned by previous researchers (Izman et al., 2012). While, the chemical composition of oxide layer formed on the Co-Cr-Mo alloy was examined using X-ray Diffraction (XRD) machine.

\subsection{Potentiodynamic polarization test}

Potentiodynamic polarization diagrams were determined using a classical three-electrode cell with specimen as a working electrode with an exposed area of about $0.402 \mathrm{~cm}^{2}$, a saturated calomel electrode (SCE) as a reference electrode and graphite as a counter electrode by employing Princeton Applied Research, US potentiostat (VersaSTAT 3300). The samples were exposed to the test solution at static and aerated condition; and equilibrated in $500 \mathrm{ml}$ Kokubo solution for 30 minutes prior to generation polarization. Megastudio Software measured the impedance in the frequency range of 5 $\mathrm{mHz}$ to $100 \mathrm{kHz}$, using perturbation amplitude of 20 $\mathrm{mV}$ around the corrosion potential. The corrosion potential ( $\left.\mathrm{E}_{\text {corr }}\right)$ and corrosion current density (icorr) were calculated from the intersection of the cathodic and anodic Tafel curves using the Tafel extrapolation method.

The test was repeated at least three times for each of sample condition. After the corrosion test, the samples were removed from the flasks and cleaned as referred from previous researcher (Mass Ayu, 2015). The samples were cleaned using ultrasonic bath in acetone for several minutes, followed by water rinsed and air blast dry in order to ensure no debris sticks on the sample surface. The bare material (comparison purposes) and oxidized samples were then characterized using field emission scanning electron microscope (FESEM) equipped with EDX attachment to yield data on 
possible degradation mechanisms of the oxide layers.

\subsection{Vickers hardness test}

The Vickers hardness test consists of indenting the sample with a diamond indenter. The diamond indenter in form of a pyramid with a square base and angle of 136 degrees between opposite faces is subjected to a load from 1 to $1000 \mathrm{~N}$. The area of the sloping surface of the indentation is calculated after the sample is indent. The Vickers hardness is the quotient obtained by dividing the load by the square $\mathrm{mm}$ area of indention. However, in this experiment, Vickers hardness value is calculated automatically by the machine. After corrosion tests each sample were later tested using Vickers hardness testing load of 50, 100 and $200 \mathrm{~N}$. Each testing load was measured for 5 times on the oxidized samples surface at different position. The average data was collected and presents in a table form.

\section{Results and discussions}

Fig. 1 represents the recorded potentiodynamic polarization plots for bare material, 3 hours and 6 hours oxidized sample of Co-Cr-Mo alloy in Kokubo solution. The corresponding corrosion parameters such as corrosion potential ( $\left.E_{\text {corr }}\right)$, corrosion current density ( $\mathrm{i}_{\text {corr }}$ ) and Tafel slopes were extracted from the curves using Tafel extrapolation method through software based approximation and listed in Table 1 . As indicated in the Tafel plots, the $E_{\text {corr }}$ of the 6 hours oxidized sample is more positive than 3 hours oxidized sample and bare material. This result means that 6 hours oxidized sample exhibits nobler Ecorr values than other samples, and thus, the oxide layer corrosion can take place in preference to the sample corrosion.

In addition, the results obtained shows that the corrosion rate of the oxidized sample at 6 hours have the slowest effect, where it only generate 0.0047335 mmpy, compare to bare material and 3 hours oxidized sample which are 0.13793 and 0.049434 mmpy respectively. According to the plotted graph, corrosion current density of oxidized sample at 3 hours is much higher than oxidized sample at 6 hours. This happened maybe due to higher pinholes and visible microcracks in the oxide layer formed on oxidized sample at 3 hours which caused low corrosion performance. Beside that it is also observed some parts of oxide layer was peel-off from the oxidized samples that may lead to increase the penetration of the solution into the oxide layer which later encourages the local attacks inside the Co-Cr-Mo alloy substrate. This phenomenon is also explained by previous researcher that using different method of surface modification (Celik et al., 2005). In addition, as the solution gets the chance to reach into the bulk material may induce a microgalvanic reaction at the oxide layer-substrate interface which accelerates the corrosion process and peel-off of the oxide layer (Guilemany et al., 2006).

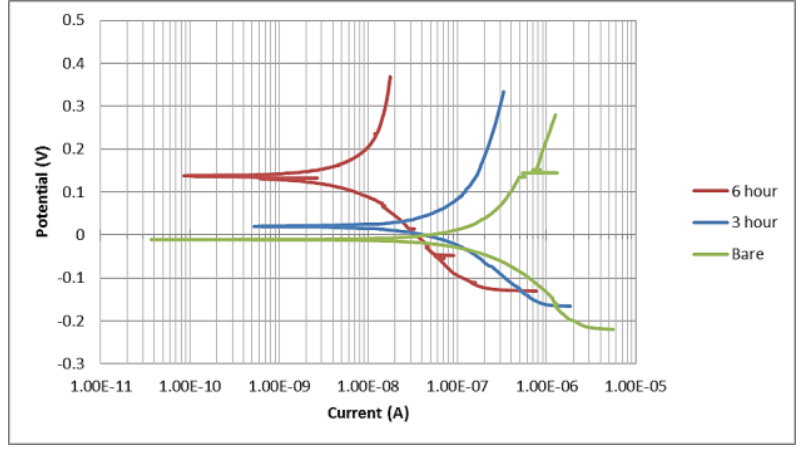

Fig. 1: Tafel plot for bare material, 3 hour and 6 hour oxidized sample of Co-Cr-Mo alloy in Kokubo solution

These effects are explained with further observation on FESEM images of oxidized sample at 3 and 6 hours. Based on the FESEM images showed in Fig. 2, it is clearly shows that oxidized sample at 6 hours duration have much bigger blocky grain size compared to oxidized sample at 3 hours. It is evident that when heats were applied at longer time caused the grain to grow denser and compact compared to shorter duration. However, when the sample undergone thermal oxidation at much higher temperature for a long duration, more $\mathrm{SiO}_{2}$ precipitates in the vicinity of the alloy which is beneath the oxide layer and at the oxide layer interface (Blau et al., 2009). This will causes most of the oxide interlayer peels-off from the substrate and not suitable for further experiments (Mas Ayu, 2015). That is why $850^{\circ} \mathrm{C}$ of oxidation temperature with 3 and 6 hours' time duration were chosen in this study.

Table 1: Tafel results for all sample conditions

\begin{tabular}{|c|c|c|}
\hline Bare material & 3 hour & 6 hour \\
\hline \multicolumn{3}{|c|}{ Corrosion Rate } \\
\hline 0.13793 mmpy & $\begin{array}{c}0.049434 \mathrm{mmpy} \\
\text { E(I=0) }\end{array}$ & $0.0047335 \mathrm{mmpy}$ \\
\hline$-252.169 \mathrm{mV}$ & $\begin{array}{l}-221.404 \mathrm{mV} \\
\text { Icorr }\end{array}$ & $-110.226 \mathrm{mV}$ \\
\hline $259.268 \mathrm{nA}$ & $\begin{array}{c}92.918 \mathrm{nA} \\
\text { Cathodic Beta }\end{array}$ & $8.897 \mathrm{nA}$ \\
\hline $186.287 \mathrm{mV}$ & $\begin{array}{l}191.915 \mathrm{mV} \\
\text { Anodic Beta }\end{array}$ & $204.312 \mathrm{mV}$ \\
\hline $397.85 \mathrm{mV}$ & $\begin{array}{r}306 \mathrm{mV} \\
\text { Chi-Square }\end{array}$ & $625.979 \mathrm{mV}$ \\
\hline 11.263 & $\begin{array}{r}7.3739 \\
\text { Fit Range }\end{array}$ & 11.06 \\
\hline$-369.2 \mathrm{mV}$ to $34 \mathrm{mV}$ & $\begin{array}{c}-407.6 \mathrm{mV} \text { to } \\
155.8 \mathrm{mV}\end{array}$ & $\begin{array}{c}-372.6 \mathrm{mV} \text { to } \\
126.6 \mathrm{mV}\end{array}$ \\
\hline
\end{tabular}

According to Fig. 3, the thickness of oxide layer formed was thicker and denser on oxidized sample at 6 hours compared to oxidation at 3 hours duration. FESEM images clearly showed that almost two folds the thickness of oxide layer formed on the sample with longer duration (6 hours). It is known that the thicker the oxide layers formed the better resistance to the corrosion effect (Mas Ayu, 2015; Igual and Mischler, 2011; Wang and Dorner-Reisel, 2004; Hanawa, 2004). Therefore, it is expected that the Kokubo solution probably could not penetrate deep into the oxide layer which explains why there is no significant interference occurred on corrosion performance and passive behaviour of the oxide 
layer. Further observations also noted that wavy oxide layer formed at shorter time (3 hours) accompany with a pinholes distributed along the layer. These pinholes are believed have influenced in corrosion rate and may cause higher release of metal ions. This finding was claimed by previous researchers as they studied different carbon content in Co-Cr-Mo alloy (Mas Ayu et al., 2013).

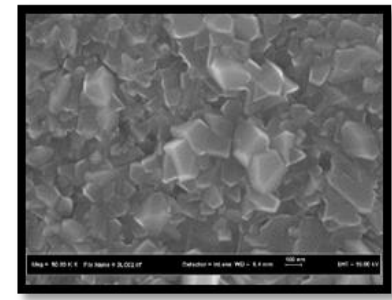

(a)

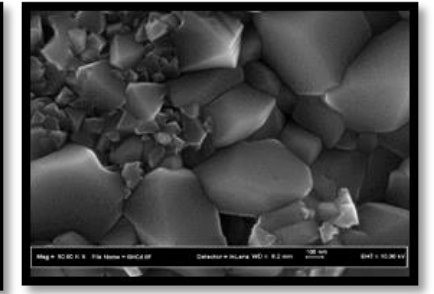

(b)
Fig. 2: 50k magnification after immersion test for (a) 3 hours oxidation sample and (b) 6 hours oxidation sample

Beside FESEM images, the element analysis also has been conducted in order to analyze oxide layer that formed on the Co-Cr-Mo substrates. Table 2 showed the EDX analysis on the bare material and the oxidized samples. The EDX was done to evaluate the sample surface before and after oxidation process.

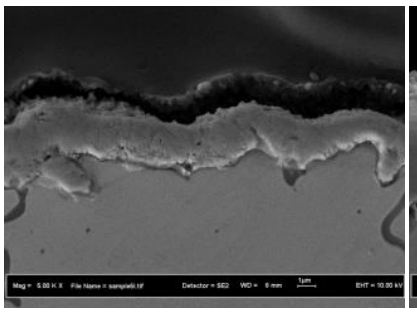

(a)

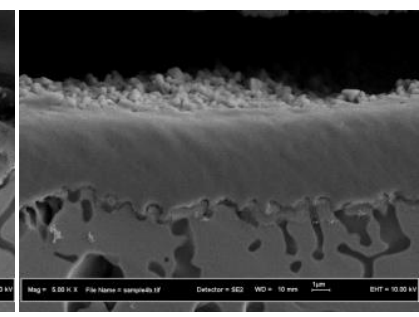

(b)
Fig. 3: Thickness oxide layer formed after oxidation process (a) oxidized sample at 3 hours and (b) oxidized sample at 6 hours (5k magnification)

Based on the results, the atomic percentage of cobalt (Co) in Co-Cr-Mo alloy has reduced almost half after thermal oxidation process compared to bare material. Initially the bare material contained atomic of Co $42.97 \%$ and has reduced significantly to $17.41 \%$ and $17.74 \%$ after oxidization at 3 hours and 6 hours respectively. This phenomenon occurred due to when constant heats supplied to the Co-Cr-Mo alloy during oxidation caused oxygen to react with bulk material and formed new composition as indicates in XRD results (Fig. 5).

In contrast, the trend for molybdenum (Mo) is different from Co. It can be seen that, the percentage of Mo reduced from $18.03 \%$ in bare material to $4.80 \%$ in 3 hours duration and to $4.83 \%$ in 6 hours duration. Similar explanation as thermal oxidation occurs more oxygen reacts with the bulk material and caused formation of thicker oxide layer accompany with new composition. It is noted that the EDX result in 6 hours showed increasing of carbon content from $0.03 \%$ to $2.69 \%$ after oxidation process is believed able to help reducing the corrosion rate and increased the hardness of the material. The carbon content detected in oxidized sample at 6 hours proved that corrosion rate can be reduced and this finding is similar with other researchers too (Mas Ayu et al., 2013; Wei et al., 2010; ASTM, 1999).

Fig. 4 showed the Vickers hardness value of oxidized samples after corrosion test in the Kokubo solution. According to the results at all testing load, oxidized samples at 6 hours performed higher value of Vickers hardness compared to bare material and oxidized samples at 3 hours. Almost double the hardness value of oxidized sample at 6 hours compared to other samples was achieved. It is also noted that the oxidized samples at 3 hours also showed the same pattern where the hardness values increase after the oxidation process. This proofs that oxide layer formed on oxidized samples not only able to increase the hardness of Co-Cr-Mo alloy but also not affected by the corrosion test.

This finding is in line with XRD results as shown in According on XRD results (Fig. 5), the highest peak is $\mathrm{Cr}_{2} \mathrm{O}_{3}$ (ICDD 38-1479) with higher intensity than other compounds. Higher percentage of oxygen in the oxidized samples occurred due to chromium (Cr) is known to have high affinity with the oxygen during oxidation process. It is also noted that the presence of other composition such as $\mathrm{Co}_{0.8} \mathrm{Cr}_{0.2}$ (ICDD 01-071-7109) on the Co-Cr-Mo substrate surface after oxidation. It is believed that even at low temperature of oxidation such as $850^{\circ} \mathrm{C}, \mathrm{Cr}$ reacted actively with other elements such as Co.

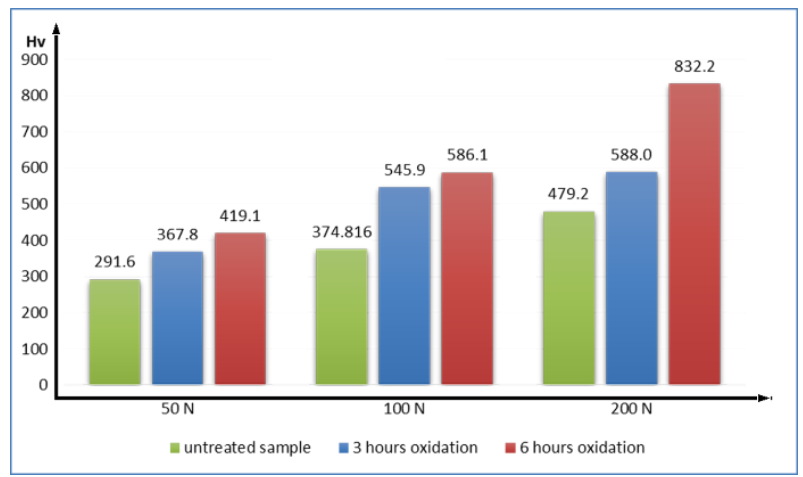

Fig. 4: The hardness value of Co-Cr-Mo samples after corrosion immersion test

Table 2: EDX of the bare material (untreated) and oxidized sample (oxide layer)

\begin{tabular}{|c|c|c|c|c|c|c|}
\hline & & 0 & Co & $\mathrm{C}$ & Mo & $\mathrm{Cr}$ \\
\hline Bare material &.$\breve{.}$ & 5.00 & 42.97 & 0.03 & 10.55 & 28.25 \\
\hline Oxidized3h & है & 44.34 & 17.41 & 0.77 & 4.80 & 21.37 \\
\hline Oxidized $6 \mathrm{~h}$ & 元 & 40.75 & 17.74 & 2.69 & 4.83 & 38.13 \\
\hline
\end{tabular}

According to periodic table, Co has high activation energy which is easier to react with $\mathrm{Cr}$ when received enough energy from the oxidation temperature. Furthermore, the percentage of Co in this material also very high which is more than $60 \%$ that caused this element to easily react with oxygen and $\mathrm{Cr}$. This finding is also similar with previous researchers where they examined oxidation temperature in wider range of temperature from 
$450 \circ \mathrm{C}$ to $1250 \circ \mathrm{C}$ at different time duration applied (Mas Ayu, 2015; Izman et al., 2012).

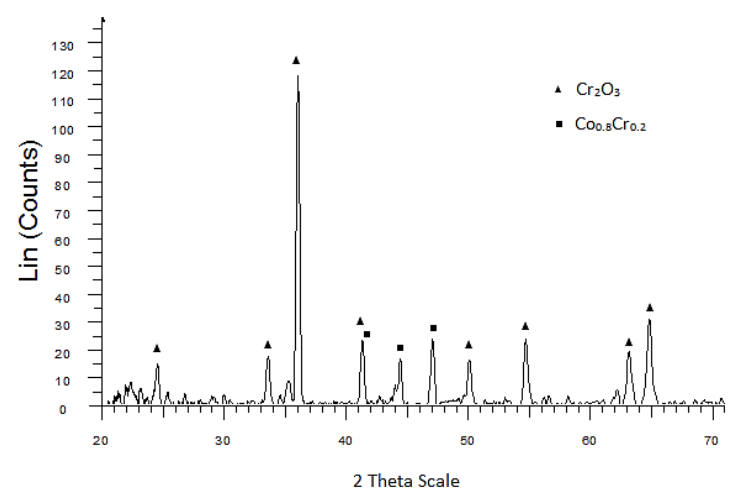

Fig. 5: XRD pattern of Co-Cr-Mo substrate after oxidation at $850 \circ \mathrm{C}$

Surface images of oxidized samples after corrosion tests were given in Fig. 6. When the FESEM images were examined, it was seen that the oxide layer was crack in oxidized sample at 3 hours and some of it was peel-off which causing higher corrosion rate obtained. This phenomenon happened probably due to non-uniform thickness of oxide layer and pinholes that distributed along the

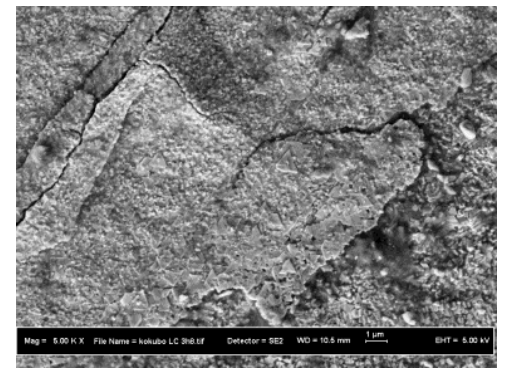

(a) oxidized surface. Consequently, when subjected to a corrosive environment such as in Kokubo solution, $\mathrm{Cr}_{2} \mathrm{O}_{3}$ layer (oxide layer) on 3 hours samples will form pitting cells at the defects at the $\mathrm{Cr}_{2} \mathrm{O}_{3}$ layer since this layer are electrochemically more stable than the bulk material. Once aggressive ions such as chloride penetrate the $\mathrm{Cr}_{2} \mathrm{O}_{3}$ layer through these small holes, driven by capillary forces, the exposed area will begin to experience anodic dissolution, which will usually extend laterally along the interface between the $\mathrm{Cr}_{2} \mathrm{O}_{3}$ layer and the bulk substrate surface. Finally the pits to be formed linked up each other, causing removal of the entire $\mathrm{Cr}_{2} \mathrm{O}_{3}$ layer by flaking and peeling (Hikmet and Hakan, 2008; Dong et al., 1997). The $\mathrm{Cr}_{2} \mathrm{O}_{3}$ layer defects such as pores, pinholes, cracks, observed at the FESEM images before corrosion tests (Fig. 3) caused the electrolyte to reach to the bulk substrate and contribute to increasing the corrosion effects. However, it is clearly showed no crack or peel-off of $\mathrm{Cr}_{2} \mathrm{O}_{3}$ layer on oxidized samples at 6 hours after corrosion test. This is believed due to thick and uniform thickness of oxide layer formed is more stable than oxidized sample at 3 hours.

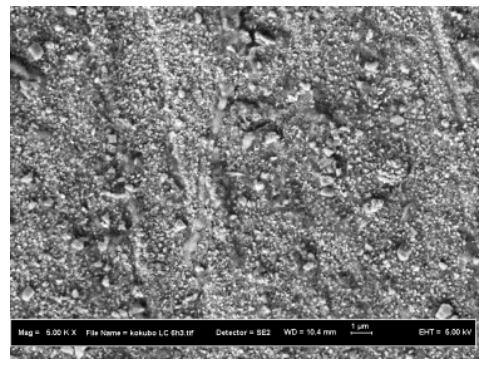

(b)

Fig. 6: FESEM images of Co-Cr-Mo substrate after oxidation at (a) 3 hours duration and (b) 6 hours duration (5k magnification)

\section{Conclusion}

This experiment has been conducted successfully by proving that thermal oxidation process is one of potential and economical method that worth to be explored. Two different duration of thermal oxidation had been applied in this experiment, which are 3 hours and 6 hours at constant temperature of $850 \circ \mathrm{C}$. The results obtained showed that by modifying the surface substrate through thermal oxidation process using optimum time and temperature able to improve its corrosion resistance. This is proved by potentiodynamic polarization plots that showed oxidized 6 hours have better corrosion resistance compared to bare material. This finding supported by the observation using FESEM and corrosion test which is clearly proved that by introducing $\mathrm{Cr}_{2} \mathrm{O}_{3}$ layer on the $\mathrm{Co}-\mathrm{Cr}-$ Mo alloy substrate able to help in sustaining the material when inserted in corrosive environment of simulated body fluids. Further in-vivo experiment will be done to test the performances of $\mathrm{Cr}_{2} \mathrm{O}_{3}$ layer in details.

\section{Acknowledgement}

This research is fully supported by research grant RDU1403118 provided by Faculty of Mechanical Engineering, Universiti Malaysia Pahang (UMP). The authors also fully acknowledged Faculty of Mechanical Engineering, Universiti Teknologi Malaysia (UTM) for providing their facilities in conducting this research respectively.

\section{References}

Afolaranmi GA, Henderson C, and Grant MH (2011). Effect of chromium and cobalt ions on phase I and phase II enzymatic activities in vitro in freshly isolated rat hepatocytes. Toxicology in Vitro, 25(1): 125-130.

Asri RIM, Harun WSW, Hassan MA, Ghani SAC, and Buyong Z (2016). A review of hydroxyapatite-based coating techniques: Sol-gel and electrochemical depositions on biocompatible metals. Journal of the Mechanical Behavior of Biomedical Materials, 57: 95-108.

ASTM (1999). Cobalt-Base alloys for biomedical applications. STP1365. American Society for Testing and Materials, Pennsylvania, USA. Available online at: 
https://www.astm.org/DIGITAL_LIBRARY/STP/SOURCE_PAG ES.OLD/STP1365_foreword.pdf

Bikramjit B and Mitjan K (2011). Overview: Bioceramics and biocomposites. In: Bikramjit B and Mitjan K (Eds.), Tribology of ceramics and composites: Materials science perspective: 211-232. John Wiley \& Sons, Hoboken, USA.

Blau PJ, Brummett TM, and Pint BA (2009). Effects of prior surface damage on high-temperature oxidation of $\mathrm{Fe}-, \mathrm{Ni}-$, and $\mathrm{Co}-$ based alloys. Wear, 267(1): 380-386.

Celik E, Ozdemir I, Avcic E, and Tsunekawa Y (2005). Corrosion behaviour of plasma sprayed coatings. Surface and Coatings Technology, 193(1): 297-302.

Dong H, Sun Y, and Bell T (1997). Enhanced corrosion resistance of duplex coatings. Surface and Coatings Technology, 90(1-2): 91-101.

Geetha M, Durgalakshmi D, and Asokamani R (2010). Biomedical implants: Corrosion and its prevention-A review. Recent Patents on Corrosion Science, 2(1): 40-54.

Giacchi JV, Morando CN, Fornaro O, and Palacio HA (2011) Microstructural characterization of as-cast biocompatible CoCr-Mo alloys. Materials Characterization, 62(1): 53-61.

Guilemany JM, Espallargas N, Suegama PH, and Benedetti AV (2006). Comparative study of $\mathrm{Cr} 3 \mathrm{C} 2-\mathrm{NiCr}$ coatings obtained by HVOF and hard chromium coatings. Corrosion Science, 48: 2998-3013.

Guocheng W and Hala Z (2010). Functional coatings or films for hard-tissue applications. Materials, 3(7): 3994-4050.

Hanawa T (2004). Metal ion release from metal implants. Materials Science and Engineering, 24(6): 745-752.

Hikmet A and Hakan S (2008). Corrosion behaviour of magnesium alloys coated with TiN by cathodic arc deposition in $\mathrm{NaCl}$ and $\mathrm{Na}_{2} \mathrm{SO}_{4}$ solutions. Materials Characterization, 59(3): 266-270.

Igual Muñoz A and Mischler S (2011). Effect of the environment on wear ranking and corrosion of biomedical CoCrMo alloys. Journal of Materials Science: Materials in Medicine, 22(3): 437-450.

Izman S, Hassan MA, Kadir MRA, Abdullah MR, Anwar M, Shah A, and Daud R (2012). Effect of pretreatment process on thermal oxidation of biomedical grade cobalt based alloy. In Advanced Materials Research, 399: 1564-1567.

Mas Ayu H, Izman S, Daud R, Krishnamurithy G, Shah A, Tomadi $\mathrm{SH}$, and Salwani MS (2017). Surface modification on CoCrMo alloy to improve adhesion strength of hydroxyapatite coating. Procedia Engineering, 184: 399-408.

Mas Ayu HM (2015). Effects of hydroxyapatite coating with oxide interlayer on bioactivity performances in CoCrMo alloy. Ph.D. Dissertation, University of Technology, Johor, Malaysia.

Mas Ayu HM, Izman S, Mohammed RAK, Rosdi D, Shah A, Mohd FMY, Shamsiah MW, Yong TM, and Kamarul T (2013). Influence of carbon concentrations in reducing $\mathrm{Co}$ and $\mathrm{Cr}$ ions release in cobalt based implant: A preliminary report. Advanced Materials Research, 845: 462-466.

Mohd Faiz MY, Mohammed RAK, Nida I, Mas Ayu H, and Rafaqat H (2014). Dipcoating of poly ( $\varepsilon$-caprolactone)/hydroxyapatite composite coating on Ti6Al4V for enhanced corrosion protection. Surface and Coatings Technology, 245: 102-107.

Paital SR and Dahotre NB (2009). Calcium phosphate coatings for bio-implant applications: Materials, performance factors, and methodologies. Materials Science and Engineering: R: Reports, 66(1): 1-70.

Shirdar MR, Taheri MM, Moradifard H, Keyvanfar A, Shafaghat A, Shokuhfar T, and Izman S (2016). Hydroxyapatite-titania nanotube composite as a coating layer on Co-Cr-based implants: Mechanical and electrochemical optimization. Ceramics International, 42(6): 6942-6954.

Tsaousi A, Jones E, and Case CP (2010). The in vitro genotoxicity of orthopaedic ceramic $\left(\mathrm{Al}_{2} \mathrm{O}_{3}\right)$ and metal (CoCr alloy) particles. Mutation Research/Genetic Toxicology and Environmental Mutagenesis, 697(1): 1-9.

Wang T and Dorner-Reisel A (2004). Effect of substrate oxidation on improving the quality of hydroxyapatite coating on CoNiCrMo. Journal of Materials Science, 39(13): 4309-4312.

Wei X, Carl L, Cecilia P, Peter T, Jukka L, and Håkan E (2010). Changes of surface composition and morphology after incorporation of ions into biomimetic apatite coatings. Journal of Biomaterials and Nanobiotechnology, 1(1): 7-16. 